\title{
Increasing the range of non-noble-metal single-atom catalysts
}

\author{
Ting Deng a, Weitao Zheng a,\#, Wei Zhang a,b,c,*
}

\section{Introduction}

Catalysis [1] plays a vital role in the chemical industries, which affect our daily life. The preparation of suitable catalysts for the selective and efficient synthesis of desired products from raw materials is important [2]. Noble metals have long been widely used as commercial catalysts because of their incomparably high activities and stabilities in heterogeneous catalysis. However, the scarcity and corresponding high prices of noble metals will make it difficult to meet the increasing demands for such catalysts. Only the surface atoms of catalysts are involved in the catalytic process because of the low coordination environment and high activity, and much effort has been devoted to downsizing metal particles to decrease costs and enhance performance [3,4]. The report in 2011 by Zhang and his group [5] of the first fabrication of a Pt single-atom catalyst (SAC) supported on iron oxide $\left(\mathrm{Pt}_{1} / \mathrm{FeO}_{x}\right)$ and its high activity and stability in CO oxidation and preferential oxidation (PROX) of CO made SACs a practical reality (Fig. 1) [6]. Since then, SACs have become one of the main focuses of catalysis research, and much effort has been devoted to the study of noble-metal SACs [7-10]. SACs provide single active sites, which give high activities and selectivities, and differ from those of conventional catalysts. They therefore could bridge the gap between homogeneous and heterogeneous catalysis. A review by Yang et al. [11]

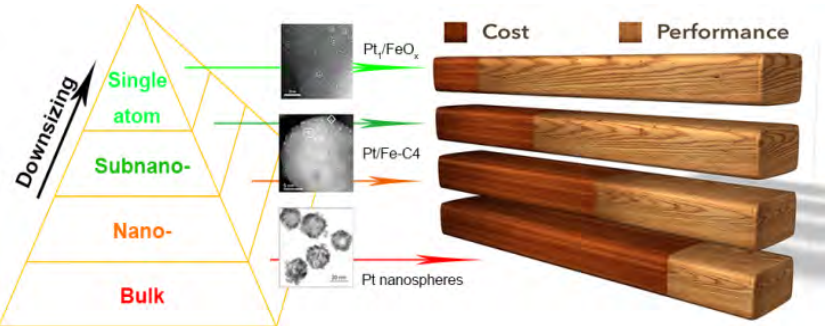

Fig. 1. Schematic diagram of catalyst downsizing from three dimensions to single atoms and corresponding typical TEM images acquired using aberration-corrected microscopes. Downsizing from three dimensions improves the catalytic performance and lowers the cost because of high utilization ratios. TEM images from top to bottom show single-atom $\mathrm{Pt}_{1} / \mathrm{FeO}_{x}, \mathrm{Pt}$ subnano-cluster, and Pt nanospheres, reproduced from Refs. [5], [3], and [4], respectively. and some other papers [12-14] have summarized progress in the preparation, characterization, and performances of SACs in various reactions. However, the question arises as to whether non-noble metals have excellent catalytic properties when they are downsized to single atoms and can completely eliminate our dependence on scarce noble metals. The answer is optimistic and research in this area indicates a promising future.

Investigations of non-noble-metal SACs have shown that some isolated transition-metal atoms give good catalytic performances. The reasons for the excellent performances of both non-noble-metal and noble-metal SACs are the same. SACs provide single active sites, which give high activities and selectivities, and differ from those of conventional catalysts. They may therefore bridge the gap between homogeneous and heterogeneous catalysis. Research on SACs has improved our understanding of such catalysts. The use of state-of-the-art tools such as subangstrom-resolution aberration-corrected scanning transmission electron microscopy (AC-STEM), X-ray absorption fine structure (XAFS) spectroscopy, and density functional theory (DFT) modeling have shown that SACs have distinctive coordination environments, quantum size effects, strong metal support interactions (SMSIs), electronic metal-support interactions (EMSIs) [15], and strong covalent metal-support interactions (CMSIs) [16]. AC-STEM is the most visual and powerful of these techniques and can provide precise structural information on individual atoms on supports. Other important methods for obtaining more information on the environments around single atoms are XAFS and extended XAFS spectroscopies. More methods need to be used and in situ characterization methods need to be developed to obtain information on processes from anchoring to reaction. A combination of theoretical calculations and these techniques will enable a better understanding of structure performance relationships.

However, the rapid replacement of noble-metal catalysts by other effective materials is not possible because noble-metal catalysts are currently dominant. The use of SACs is the most efficient way to lower costs and boost performance simultaneously, and research has mainly focused on noble metals. The future development of non-noble-metal catalysts that could completely replace noble-metal catalysts is important [17-27]. 
The catalytic performances of larger-dimensional non-noble metals are relatively poor, which is probably why less effort has been devoted to non-noble metal SACs. However, they are promising in the long term. From this perspective, we aim to introduce the concept and promote the understanding of SACs, and summarize the most recent progresses in non-noble-metal SACs.

\section{Origins of superior performances of SACs and interactions with supports}

Isolated single-metal atoms on various supports provide active sites for heterogeneous catalysis. The excellent performances of these catalysts originate from their enhanced utilization ratios, and the well-dispersed single atoms, which spare multi-active sites within active particles. However, the high surface free energy of a single atom, resulting from size reduction, leads to deactivation and easy sintering under industrial conditions. An appropriate support that interacts with SACs, like a strong hand grasping single atoms, is needed to achieve an excellent catalytic performance. Various materials such as metal oxides $[7,28]$, metals $[9,29]$, graphene $[23,26]$, carbon nitrides [30], and $\mathrm{MoS}_{2}$ [31] have been used as supports to clarify the roles of interfaces. SMSIs are not only critical for SACs to prevent high mobility and easy sintering in practical applications, but also affect the entire catalytic process. There are two main categories of SMSIs, namely those arising from surface structural defects, and those stemming from electronic defects. For both non-noble-metal and noble-metal SACs, SMSIs hold single atoms and enable them to predominate, but there are many questions to be answered, e.g., the effects on sintering resistance and electron transfer. Recent advances have improved our understanding of SACs.

\subsection{Metal oxide supports}

Metal oxides such as $\mathrm{FeO}$ [5] or $\mathrm{CeO}_{2}$ [7] are usually used as the supports for SACs. Qiao et al. [16] used $\mathrm{FeO}$ to support $\mathrm{Au}$ atoms, which showed extremely high stability in CO oxidation. Theoretical studies have shown that this stability arises from the formation of CSMIs by positively charged Au atoms; these results increase our understanding of the catalytic process. Surface defects on metal oxides can serve as anchoring sites for single atoms, but a prerequisite for further understanding SACs is the identification of specific anchoring sites on supports and how they react [28,32]. Dvorak et al. [28] prepared Pt SACs on ceria and used systematic DFT calculations to show that step edges, rather than oxygen vacancies, on ceria provide thermally and chemically stable sites for Pt ions. The step edges stabilize $\mathrm{Pt}^{2+}$ species in planar $\mathrm{PtO}_{4}$ moieties, with an excess of $\mathrm{O}$ atoms on both steps I-O and II-O (Fig. 2(c) and (d)). Unlike the stoichiometric steps I-S and II-S (Fig. 2(a) and (b)), steps I-O and II-O bypass the reduction of surface Ce atoms from $\mathrm{Ce}^{4+}$ to $\mathrm{Ce}^{3+}$; a larger coverage by $\mathrm{Pt}^{2+}$ can therefore be obtained without nucleation of metallic Pt clusters. In accordance with the calculation, Pt single atoms on the oxide surfaces of ceria have shown high thermal stabilities because the single atoms are trapped in these defects [7] (Fig. 2(e)). Metal oxides with ubiquitous defects on their surfaces can be designed, and metal oxides with controlled defects are an excellent choice for preparing ultra-stable SACs.

\subsection{Metal supports}

Catalytically active metal atoms can be atomically dispersed on the surface layer of a more inert host metal to stabilize single atoms and enhance the catalytic performance. In the industrially important hydrogenation of 1,3-butadiene, $\mathrm{Pt} / \mathrm{Cu}$ alloys
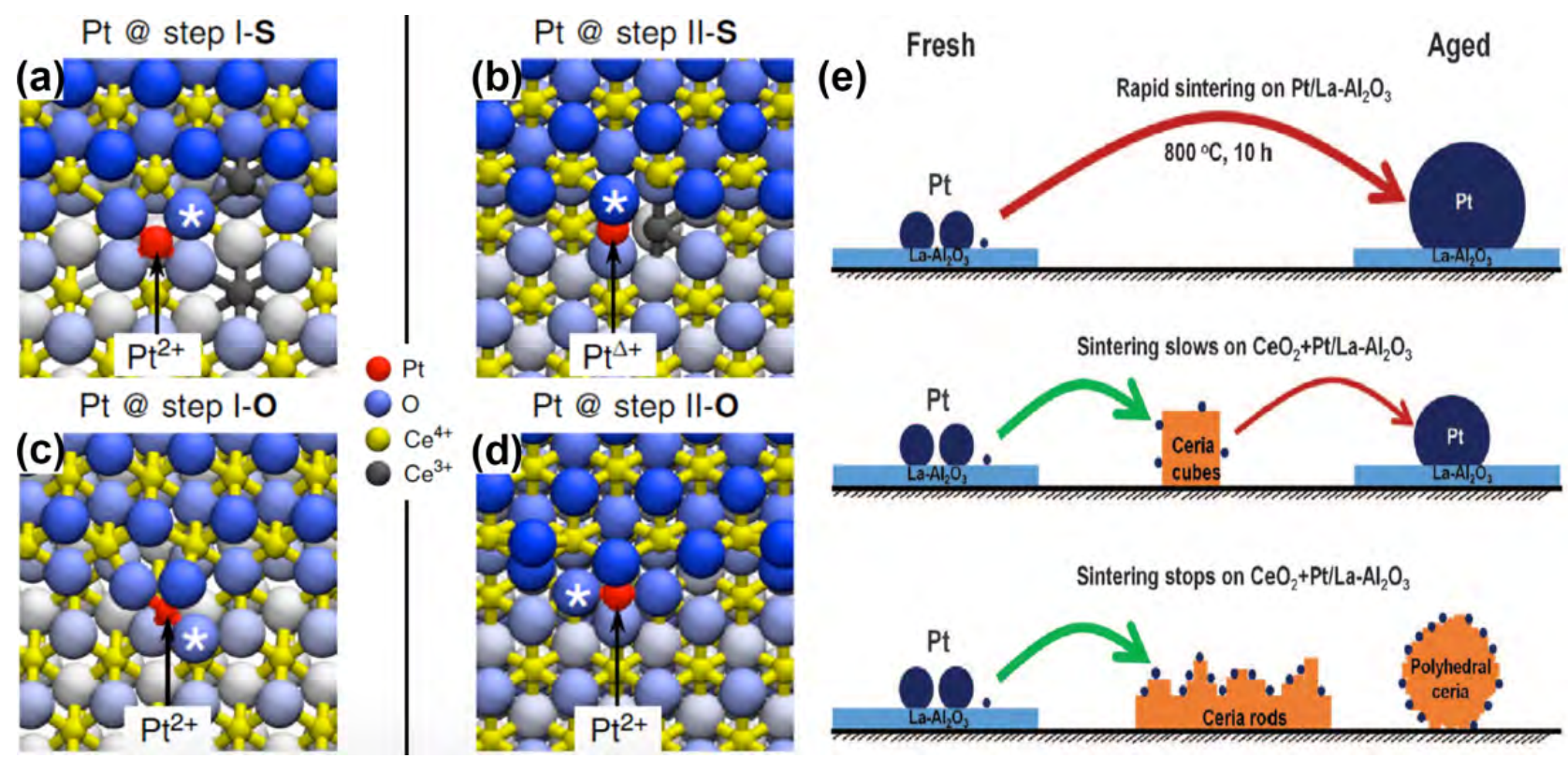

Fig. 2. (a) Pt adatom at stoichiometric step I (step I-S) and (b) at stoichiometric step II (step II-S); (c) Pt adatom at step I with excess O (step I-O) and (d) at step II with excess O (step II-0); (e) Illustration of how Pt on ceria can suppress sintering. Reproduced from Refs. [28] and [7]. 

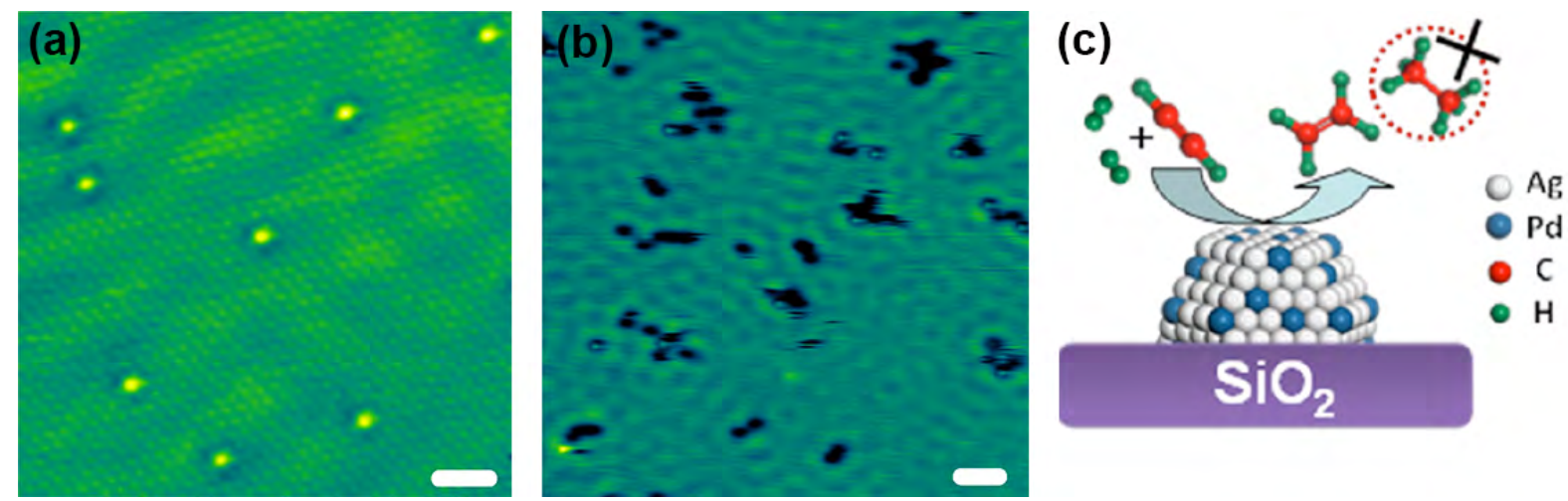

Fig. 3. (a) STM image of $\mathrm{Pt} / \mathrm{Cu}(111)$ surface with $\mathrm{Pt}$ substituted into $\mathrm{Cu}(111)$ surface. (Scale bar, $1 \mathrm{~nm}$ ); (b) $\mathrm{H}$ atom spillover onto $\mathrm{Cu}$; $\mathrm{H}$ atoms appear as depressions and cluster into small mobile islands. (Scale bar, $3 \mathrm{~nm}$ ); (c) Single Pd atoms alloyed with Ag give high selectivity and excellent performance in acetylene hydrogenation. Reproduced from Refs. [9] and [33].

are often used as modified catalysts but large Pt ensembles on the $\mathrm{Cu}$ surface reduce the selectivity. At lower loadings, individual, isolated $\mathrm{Pt}$ atoms that are substituted into the $\mathrm{Cu}(111)$ surface as SACs can activate the dissociation and spillover of $\mathrm{H}$ to $\mathrm{Cu}$ (Fig. 3(a) and (b)), resulting in high selectivity because of the weak binding of butadiene to $\mathrm{Cu}(9)$. Pd nanoparticles are regarded as the most active materials for acetylene hydrogenation, but give low selectivity for ethylene because of adsorption on contiguous Pd sites. A SAC consisting of isolated Pd atoms on a Ag surface were prepared by Pei et al. [33] and showed high selectivity in acetylene hydrogenation in excess ethylene (Fig. 3(c)). The electronic structures of atoms change when they are doped into hosts, and this affects their properties. This work showed that alloying single Pd atoms with Ag can modify both the local structural and electronic environments of $\mathrm{Pd}$ sites, and the synergetic effects of geometric and electronic changes facilitate hydrogenation and decreases adsorption. Alloy catalysts are therefore suitable for preparing efficient SACs because of their metal metal interactions.

\subsection{Other materials as supports}

Other materials besides metals and metal oxides have been used as supports. Graphene [22,26] and carbon nitrides [30] have been widely used to support SACs. Graphene is inert under hydrogen evolution reaction (HER) conditions, but the incorporation of single Ni and Pt atoms results in a catalyst with excellent stability and activity. Graphyne is built up from $s p$ and $s p^{2}$ networks, and this gives it multiple advantages such as a high surface area, uniform pores, tunable electronic properties, and chemical stability [32]. Recently, graphyne has been shown to be a promising support for SACs because of its strong interactions with single atoms [34]. Metal organic frameworks [35] (MOFs) are also used as supports [25] or precursors [24]. The interactions between single atoms and the substrate not only stabilize single atoms, but can also be used to tune the substrate properties. There is a consensus that the perfect in-plane domain of $\mathrm{MoS}_{2}$ is inert, but Deng et al. [31] reported activity in the HER of the in-plane $S$ atoms of $\mathrm{MoS}_{2}$ by single atom doping.

In the future, the design of new supports such as MXene
[36], with more delicate decorations and novel morphologies may further improve the catalytic performances of SACs. The supports we have mentioned provide the platforms on which stabilized single atoms can serve as homogeneous active sites with unparalleled performances. However, most SAC studies have focused on noble metals because of the dominance of noble metals in catalysis, and there have been many in-depth investigations of the interactions between single atoms and supports for noble metals. SAC formation on supports by the more active transition metals is more difficult than in the case of noble metals. The development of supports for the preparation of non-noble-metal SACs is therefore important. A deeper understanding of these interactions is needed to trigger new preparation methods. Wet chemistry methods $[5,23]$ and atomic layer deposition $[8,37]$ have been successfully used to prepare SACs. Advanced and efficient methods that enable the synthesis of precisely modified SACs with single atoms intimately anchored to the support are needed. Electrochemical methods might provide convenient tools for SAC preparation. This would further increase our understanding of SACs and enable progress in the precise control of SACs.

\section{Recent progresses in non-noble-metal SACs}

Non-noble-metal catalysts are important for long-term sustainable development, but the performances of such catalysts are currently inferior to those of noble-metal catalysts and far from satisfying our needs. However, the SAC concept not only paves the way for enhancing the catalytic activities and reducing the costs of noble-metals catalysts, but also potentially enables the development of non-noble-metal SACs with good properties, perhaps even comparable to those of commercial noble-metal catalysts.

Computational studies have been used to investigate the use of various SACs supported on $\mathrm{FeO}_{x}$ in PROX [27]. Among all the considered SAC systems (Fig. 4), $\mathrm{Ru}_{1} / \mathrm{FeO}_{x}$ performed best in CO oxidation because of its low activation energy vacancies. Vacancy-free $\mathrm{Co}_{1} / \mathrm{FeO}_{x}$ and $\mathrm{Ti}_{1} / \mathrm{FeO}_{x}$ gave comparable performances based on a Langmuir Hinshelwood (LH) mechanism and similar reaction routes (Fig. 4(e)), in which $\mathrm{O}_{2}$ and $\mathrm{CO}$ are 


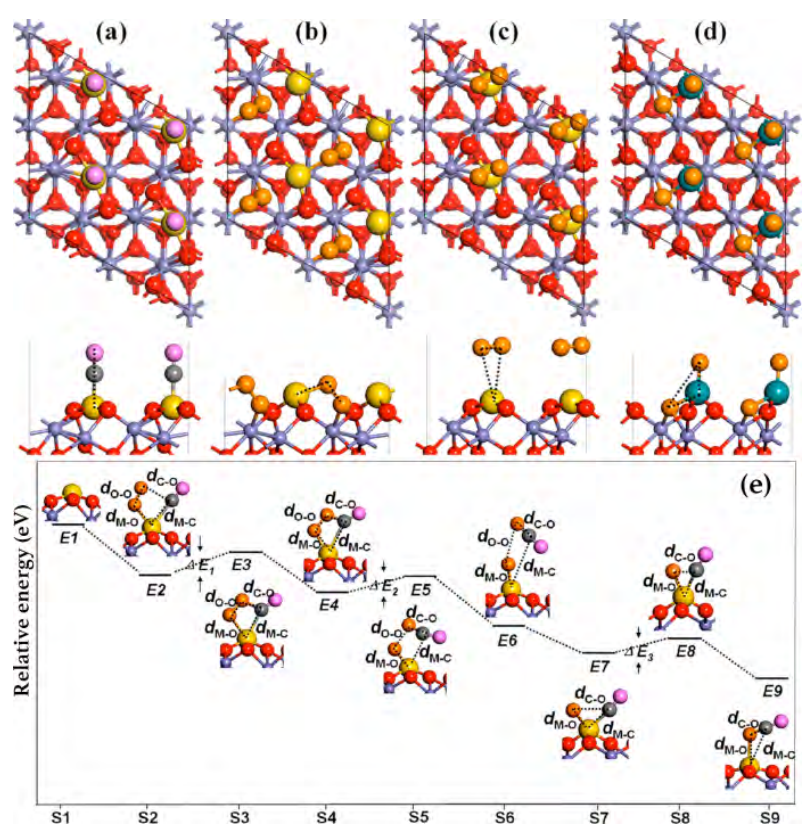

Fig. 4. (a) Top and side views of schematic diagram of energetically most favorable configurations of $\mathrm{CO}$ adsorbed on oxygen-defective $\mathrm{M}_{1} / \mathrm{FeO}_{x}\left(\mathrm{M}=\mathrm{Au}, \mathrm{Rh}, \mathrm{Pd}, \mathrm{Co}, \mathrm{Cu}\right.$, and $\mathrm{Ru}$ ); (b) $\mathrm{O}_{2}$ adsorbed on oxygen-defective $\mathrm{M}_{1} / \mathrm{FeO}_{x}\left(\mathrm{M}=\mathrm{Rh}, \mathrm{Pd}, \mathrm{Co}\right.$, and $\mathrm{Cu}$ ); (c) $\mathrm{Au}_{1} / \mathrm{FeO}_{x}$. (d) $\mathrm{Ru}_{1} / \mathrm{FeO}_{x}$; (e) Reaction pathway for $\mathrm{CO}$ oxidation on vacancy-free $\mathrm{M}_{1} / \mathrm{FeO}_{x}(\mathrm{M}=\mathrm{Ru}, \mathrm{Rh}, \mathrm{Pd}, \mathrm{Co}$, and $\mathrm{Ti})$ via $\mathrm{LH}$ mechanism. Color scheme: $\mathrm{M}$, gold; $\mathrm{Ru}$, cyan; $\mathrm{O}$ of $\mathrm{CO}$, pink; $\mathrm{O}$ of $\mathrm{O}_{2}$, orange; $\mathrm{O}$ of iron oxide support, red; Fe, purple. Reproduced from Ref. [27].

first co-adsorbed, and then cross an energy barrier to generate intermediates on $\mathrm{M}$ with release of $\mathrm{CO}_{2}$. Production of a second $\mathrm{CO}_{2}$ molecule needs another barrier to be overcome. Ultimately, the best way to minimize the cost of noble metals is to use other, much cheaper metals. Simulations using $\mathrm{Co}_{1} / \mathrm{FeO}_{x}$ and $\mathrm{Ti}_{1} / \mathrm{FeO}_{x}$ showed the possibility of non-noble metals replacing noble metals in catalytic processes. The potential use of non-noble SACs has increased the range of transition metals studied. A series of $3 d$ single transition-metal atoms (STMAs, M = Sc to Zn) supported on a ceria (111) surface were investigated as SACs for water adsorption and dissociation [21]. The results show that the greater the number of electrons transferred from the STMA to the substrate, the stronger the binding energies are between the STMA and the ceria surfaces. Consideration of all factors indicates that $\mathrm{Zn}, \mathrm{Cr}$, and $\mathrm{V}$ are potential candidates for water dissociation. In another study, this series of STMAs supported on $\mathrm{C}_{2} \mathrm{~N}$ were investigated as SACs for CO oxidation [17]. The results show that these $3 d$ transition metals (Sc, Ti, V, Cr, and Mn) behave differently, probably because of interactions arising from electron transfer with the substrate. $\mathrm{Cr}$ - and Mn-embedded $\mathrm{C}_{2} \mathrm{~N}$ monolayers are best because the calculated energy barriers are only 0.59 and $0.64 \mathrm{eV}$ for low-temperature CO oxidation, respectively, whereas a Ni SAC is not promising. In another study [20], the catalytic activity of $\mathrm{Ni}_{1} / \mathrm{FeO}_{x}$ in $\mathrm{CO}$ oxidation was comparable to that of $\mathrm{Pt}_{1} / \mathrm{FeO}_{x}$, the first prepared SAC, and better than that of $\mathrm{Ir}_{1} / \mathrm{FeO}_{x}$. A comparison of these two studies clearly shows that the support greatly affects the catalytic performance. The interactions between atoms and supports are the key processes that are im- portant in the performance. It is still not possible to know whether a substrate is the best and what the conditions for a perfect substrate for a certain element are.

Water splitting is a clean solution for renewable energy production. Much effort has been devoted to finding a low-cost, durable, and efficient catalyst for the oxygen evolution reaction. $\mathrm{Co} / \mathrm{Ni}$ single atoms supported on graphitic carbon nitride provide an ideal alternative electrocatalyst to traditional $\mathrm{Pt}, \mathrm{IrO}_{2}$, and $\mathrm{RuO}_{2}$ materials [19]. The lowest overpotential is only 0.16 V. Large-scale application of the other half-reaction, i.e., the HER, also needs the development of inexpensive and efficient catalysts. In 2015, Fei et al. [23] used a simple wet chemistry method in which graphene oxides and cobalt salts, used as precursors, were reduced in $\mathrm{NH}_{3}$ to synthesize a Co SAC. The Co atoms were atomically dispersed in the nitrogen-doped graphene substrate and $\mathrm{N}$ atoms were coordinated with Co. The catalyst is robust and highly active in aqueous media, with a low overpotential $(0.03 \mathrm{~V})$. The synergetic effect between Co and $\mathrm{N}$ atoms could be further optimized to tune the catalytic performance. The activity is still much lower than that of commercial Pt/C, but it represents progress toward replacing Pt catalysts. Simultaneously, Qiu et al. [26] synthesized graphene doped with a single $\mathrm{Ni}$ atom for the HER in acidic solutions (Fig. 5). $\mathrm{Ni}$ is known to be a suitable catalyst for the HER in alkaline solutions, thus the stability of $\mathrm{Ni}$ in acidic media depends on the
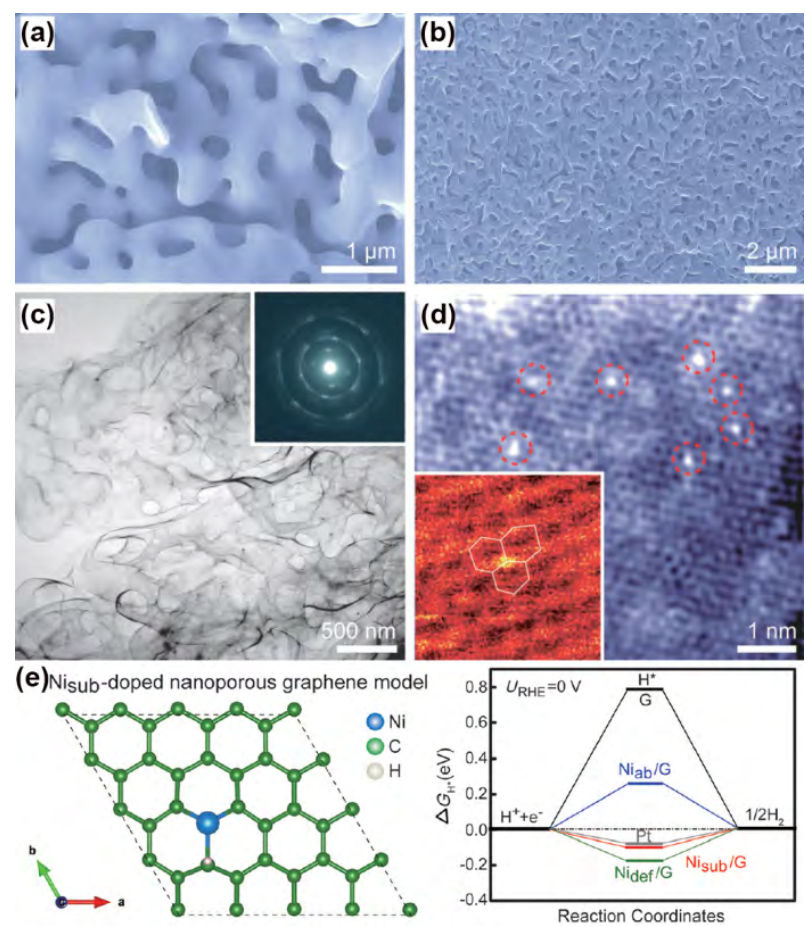

Fig. 5. SEM images of (a) as-prepared np-Ni/graphene composite and (b) Ni-doped np-G after Ni dissolution for $6 \mathrm{~h}$; (c) TEM image of Ni-doped np-G. (Inset: selected area electron diffraction pattern); (d) High-angle annular dark field-STEM image of Ni-doped graphene. (Inset Enlarged high-angle annular dark field-STEM image (red circle), which shows substituted $\mathrm{Ni}$ atom (bright orange spot) occupying carbon site in graphene lattice (white lines)); (e) Hydrogen adsorption sites and configuration of Nisub/G model with $\Delta \mathrm{G}_{\mathrm{H}^{*}}=-0.10 \mathrm{eV}$ (left) and calculated Gibbs free energy diagram (right) for HER at equilibrium potential for Pt catalyst and Ni-doped graphene samples. Reproduced from Ref. [26]. 
specific properties of single Ni atoms. Experimental and theoretical investigations showed that the stability originates from $s p d$ orbital charge transfer between $\mathrm{Ni}$ atoms and the surrounding carbon atoms, which contributes to the catalytic performance. The Ni atoms are physically adsorbed on the hollow centers of graphene, and the corresponding electronic state of the Ni graphene system shows a positive Gibbs free energy for $\mathrm{H}^{*}$ adsorption (Fig. 5(e)). The single-atom Ni dopants anchored to graphene show superior HER activity with a low overpotential of $\sim 50 \mathrm{mV}$. In $\mathrm{H}_{2} \mathrm{SO}_{4}$ solution $(0.5 \mathrm{~mol} / \mathrm{L})$, the Tafel slope is $45 \mathrm{mV} /$ dec.

Metal atom loadings are low to prevent aggregation to clusters, and this hampers further study of SACs. Increasing the metal loadings requires a deeper understanding of the anchoring sites and coordination environments, and new supports or synthetic methods may be needed. MOFs, which consist of metal centers and organic linkers, are structurally tunable [35]. Recently, Yin et al. [25] pyrolyzed ZIF-7 with Zn partially substituted by Co to synthesize a Co SAC supported on a three-dimensional N-doped carbon framework (Fig. 6). Substitution of $\mathrm{Zn}$ leads to a homogeneous distribution of $\mathrm{Zn}$ and Co in the framework. Selectively evaporating $\mathrm{Zn}$ atoms enables control of the Co loading and manipulation of the distances between adjacent Co atoms to prevent aggregation. Because the precursor is three dimensional, the Co atoms are present not only on the surface but also in the bulk. The obtained Co $\mathrm{N}_{x}$ single sites give good oxygen reduction reaction (ORR) performances with a half-wave potential $(0.881 \mathrm{~V})$ that is more positive than those of commercial Pt/C $(0.811 \mathrm{~V})$ and most reported non-noble-metal catalysts. The thermal and chemical stabilities are also excellent.

Zhang et al. [24] implanted single Co atoms into a MOF structure (Fig. 7); it showed high activity in $\mathrm{CO}_{2}$ reduction to $\mathrm{CO}$ and $\mathrm{CH}_{4}$. This implantation strategy combined a large surface area and strong $\mathrm{CO}_{2}$ adsorption ability with the excellent catalytic activity of SACs to improve the overall performance. The migration of photogenerated excitations to Co centers facilitates charge separation in the semiconducting MOF and supplies energetic electrons to gas molecules adsorbed on the

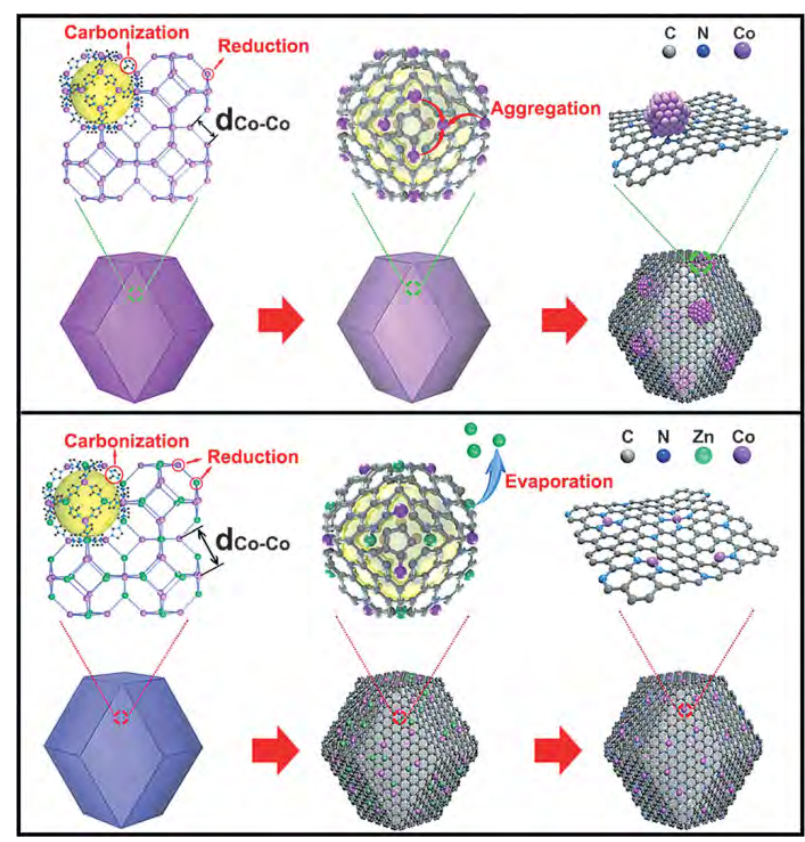

Fig. 6. Formation of Co nanoparticles (top) and Co single atoms (bottom) on N-doped carbons. Reproduced from Ref. [25].

MOF. The versatility of MOFs may enable the development of more advanced SACs that can be used in a broad range of applications. Incorporating SACs with MOFs is a successful example and MOFs with tunable structures provide a new strategy for the design and preparation of SACs.

Cui et al. [22] synthesized various single-site transition-metal ( $\mathrm{Mn}, \mathrm{Fe}, \mathrm{Co}, \mathrm{Ni}$, and $\mathrm{Cu}$ ) graphene composites used in DSCs. The catalytic activity and stability of the Co-doped composite were higher than those of the commercial Pt counterpart (Fig. 8). These superior properties are the result of the appropriate adsorption energies of dyes on the confined Co sites, which balance the adsorption and desorption processes. This study also showed the potentials of other transition metals for use as active centers. These results are promising for the elimination of noble-metal SACs in the future. The differences
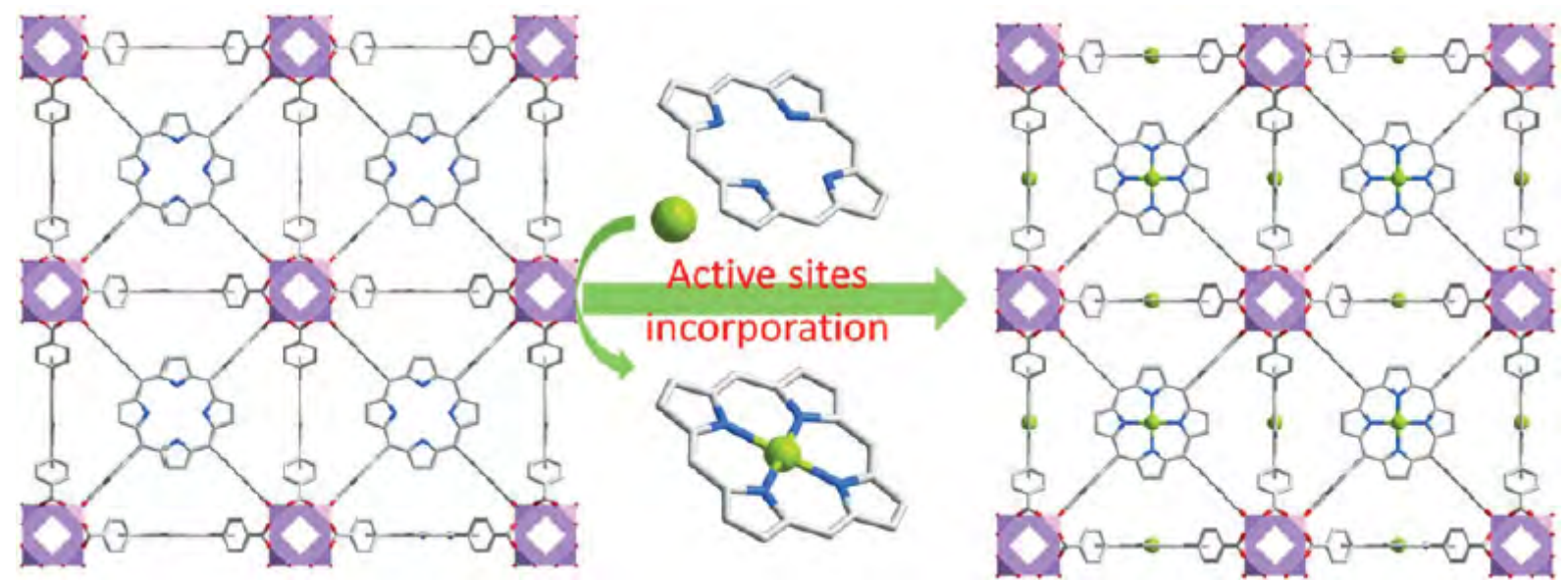

Fig. 7. View of three-dimensional network of MOF-525-Co featuring highly porous framework and incorporated active sites. Reproduced from Ref. [24]. 

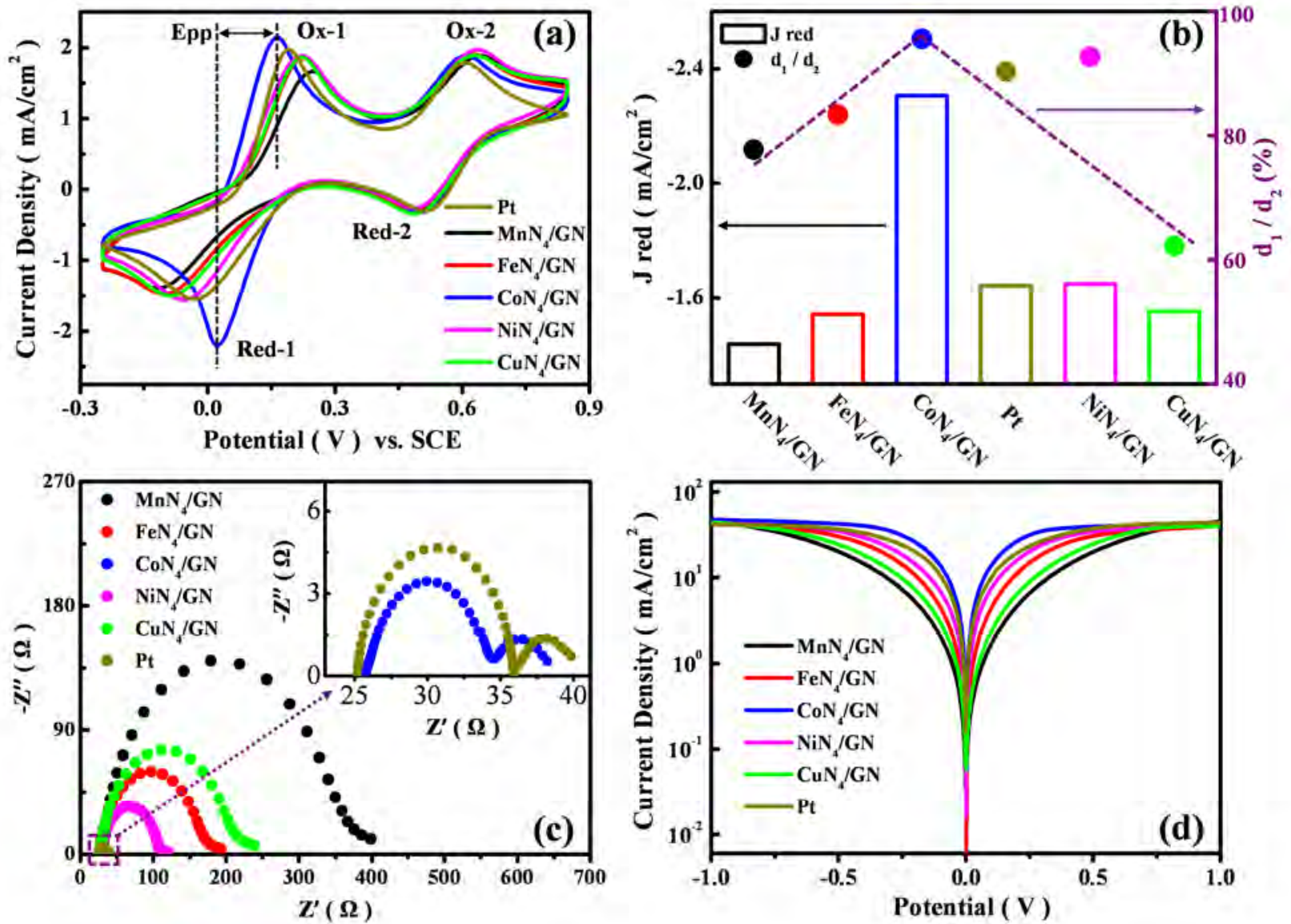

Fig. 8. IRR performances of MN4/GN composites ( $\mathrm{M}=\mathrm{Mn}, \mathrm{Fe}, \mathrm{Co}, \mathrm{Ni}$, or $\mathrm{Cu}$ ) and standard Pt electrode. (a) Cyclic voltammograms; (b) Reduction current density for IRR in symmetric cells, and counter electrode durability tests based on d1/d2 ratio of semicircle diameter; (c) Electrochemical impedance spectra; (d) Tafel polarization curves for symmetric cells. Reproduced from Ref. [22].

among the catalytic performances depend on the intrinsic natures of the non-noble metals, which make them more prone to agglomeration or to reacting with oxygen; this results in further decreases in their catalytic activities or provides them with unexpected SAC performances. There have been few systematic, comprehensive, and in-depth investigations of non-noble SACs. The replacement of noble-metal catalysts needs more fundamental theoretical calculations and practical experiments to be conducted to provide guidelines on selecting potential candidates for transition-metal SACs. Furthermore, because of their intrinsic properties, modified methods and novel ideas need to be used to achieve controlled and convenient preparation of non-noble-metal SACs. Based on preparations, more in-depth calculations should be performed to study the details of different elemental atoms. Different anchoring sites for various non-noble metals to those for noble-metal SACs could enable tuning of the bond energy, electron transfer, bond length, and reaction conditions. Gas adsorption processes and reaction paths and the corresponding energy conversions need to be simulated to unravel the mechanisms. A combination of practical experiments and theoretical studies is a productive way to fill the gaps in our understanding of non-noble SACs, and also lay the foundations for the future design of non-noble SACs.

\section{Perspectives and conclusions}

In terms of SACs, only a small number of finely isolated single atoms can give the same or superior catalytic performances of currently used materials. Non-noble-metal catalysts are the best option for ultimately eliminating concerns regarding the scarcity and high cost of noble-metal catalysts. Although much progress has been made, many issues still need to be explored.

(I) The performances of SACs on different supports vary for one reaction, therefore the substrates are indirectly involved in the catalytic process. How are they involved, especially in non-noble SACs?

(II) Theoretical and experimental studies have shown that Co and Ni SACs have a promising future. However, although the members of the iron-series elements share similar electronic configurations, Fe is not a leading candidate for SACs. There is only a difference of one electron between these three elements. So, another question arises: does the number of electrons affect the performance?

(III) The anchoring sites of single atoms remain elusive. 
STEM images show that single atoms are randomly anchored on supports, leaving plenty of unoccupied space. A higher utilization ratio by supports can also greatly enhance the overall performance. The higher reactivities of transition metals make SAC preparation more difficult. Consequently, much effort should be devoted to investigating the interactions between transition-metal atoms and various supports because different electronic configurations can trigger new interactions. In turn, our understanding of SACs needs to be developed, leading to more advanced synthetic methods and the precise development of supports with single atoms. However, because of their better activities, non-noble transition-metal elements can take part in more reactions, with more resultant structures, which could also be an advantage in developing novel synthetic routes.

Usually, combining different processes in one catalyst material requires different equipment and procedures. This can increase the cost and the material may not be stable and active in harsh industrial environments. However, because of the interactions between the supports and single atoms, bifunctional or multi-functional SACs can avoid unfavorable phase changes between different catalytic processes. They therefore remain stable, which further reduces the costs and enhances the efficiencies of single atoms and supports. The application range of SACs is therefore being expanded to meet the needs for multi-functional active metal sites.

SACs involve downsizing to the ultimate limit, and can therefore unlock the potential of non-noble metals to replace noble-metal catalysts. Although many issues need to be further discussed, recent studies have provided a fundamental understanding not only of synthesis and performance, but also of the origin of the superior properties and factors that influence synthesis and performance. It is expected that many more non-noble-metal SACs with improved performances will be produced for a wider range of applications.

\section{Wei Zhang}

a State Key Laboratory of Automotive Simulation and Control, Department of Materials Science, and Key Laboratory of Mobile Materials MOE, Jilin University, Changchun 130012, Jilin, China; b CIC Energigune, Parque Tecnológico de Álava, Albert Einstein 48, Miñano 01510, Spain;

c Ikerbasque, Basque Foundation for Science, Bilbao 48013, Spain

Tel/Fax: +86-431-85168246

weizhang@jlu.edu.cn

\section{Weitao Zheng}

a State Key Laboratory of Automotive Simulation and Control, Department of Materials Science, and Key Laboratory of Mobile Materials MOE, Jilin University, Changchun 130012, Jilin, China E-mail: wtzheng@jlu.edu.cn

Received 23 January 2017

Published 5 September 2017

DOI: 10.1016/S1872-2067(17)62799-2

\section{References}

[1] J. M. Thomas, K. D. M. Harris, Energy Environ. Sci., 2016, 9, 687-708.

[2] M. S. Faber, S. Jin, Energy Environ. Sci., 2014, 7, 3519-3542.

[3] B. T. Qiao, A. Q. Wang, L. Li, Q. Q. Lin, H. S. Wei, J. Y. Liu, T. Zhang, ACS Catal., 2014, 4, 2113-2117.

[4] H. P. Liang, H. M. Zhang, J. S. Hu, Y. G. Guo, L. J. Wan, C. L. Bai, Angew. Chem. Int. Ed., 2004, 43, 1540-1543.

[5] B. T. Qiao, A. Q. Wang, X. F. Yang, L. F. Allard, Z. Jiang, Y. T. Cui, J. Y. Liu, J. Li, T. Zhang, Nat Chem., 2011, 3, 634-641.

[6] J. M. Thomas, Z. Saghi, P. L. Gai, Top Catal., 2011, 54, 588-594.

[7] J. Jones, H. F. Xiong, A. T. Delariva, E. J. Peterson, H. Pham, S. R. Challa, G. S. Qi, S. Oh, M. H. Wiebenga, X. I. P. Hernandez, Y. Wang, A. K. Datye, Science, 2016, 353, 150-154.

[8] N. C. Cheng, S. Stambula, D. Wang, M. N. Banis, J. Liu, A. Riese, B. W.

\section{Graphical Abstract}

Chin. J. Catal., 2017, 38: 1489-1497 doi: 10.1016/S1872-2067(17)62799-2

\section{Increasing the range of non-noble-metal single-atom catalysts}

Ting Deng, Weitao Zheng *, Wei Zhang*

Jilin University, China; CIC Energigune, Parque Tecnológico de Álava, Spain;

Ikerbasque, Basque Foundation for Science, Spain

The catalytic performances of non-noble metals are inferior to those of noble metals. The advent of single-atom catalysts (SACs) has shifted the balance. Experimental and theoretical studies have shown that non-noble-metal SACs have a promising future in various key reactions.

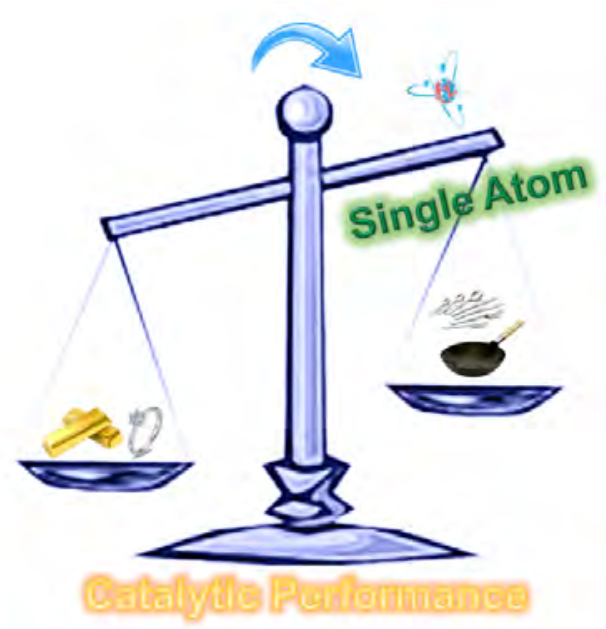


Xiao, R. Y. Li, T. K. Sham, L. M. Liu, G. A. Botton, X. L. Sun, Nat. Commun, 2016, 7, 13638.

[9] F. R. Lucci, J. L. Liu, M. D. Marcinkowski, M. Yang, L. F. Allard, M. Flytzani-Stephanopoulos, E. C. H. Sykes, Nat. Commun, 2015, 6, 8550

[10] H. S. Wei, X. Y. Liu, A. Q. Wang, L. L. Zhang, B. T. Qiao, X. F. Yang, Y. Q. Huang, S. Miao, J. Y. Liu, T. Zhang, Nat. Commun, 2014, 5, 5634.

[11] X. F. Yang, A. Q. Wang, B. T. Qiao, J. Li, J. Y. Liu, T. Zhang, Acc. Chem. Res., 2013, 46, 1740-1748.

[12] W. Zhang, W. T. Zheng, Adv. Funct. Mater., 2016, 26, 2988-2993.

[13] C. Y. Wang, M. Yang, M. Flytzani-Stephanopoulos, Aiche J., 2016, $62,429-439$.

[14] B. T. Qiao, J. X. Liang, A. Q. Wang, J. Y. Liu, T. Zhang, Chin. J. Catal., 2016, 37, 1580-1587.

[15] P. P. Hu, Z. W. Huang, Z. Amghouz, M. Makkee, F. Xu, F. Kapteijn, A. Dikhtiarenko, Y. X. Chen, X. Gu, X. F. Tang, Angew. Chem. Int. Ed., 2014, 53, 3418-3421.

[16] B. T. Qiao, J. X. Liang, A. Q. Wang, C. Q. Xu, J. Li, T. Zhang, J. Y. Liu, Nano Res., 2015, 8, 2913-2924.

[17] D. W. Ma, Q. G. Wang, X. Y. Yan, X. W. Zhang, C. Z. He, D. W. Zhou, Y. N. Tang, Z. S. Lu, Z. X. Yang, Carbon, 2016, 105, 463-473.

[18] W. Q. Liu, L. L. Zhang, W. S. Yan, X. Y. Liu, X. F. Yang, S. Miao, W. T. Wang, A. Q. Wang, T. Zhang, Chem. Sci., 2016, 7, 5758-5764.

[19] X. Y. Li, P. Cui, W. H. Zhong, J. Li, X. J. Wang, Z. W. Wang, J. Jiang, Chem. Commun., 2016, 52, 13233-13236.

[20] J. X. Liang, X. F. Yang, A. Q. Wang, T. Zhang, J. Li, Catal. Sci. Technol,, 2016, 6, 6886-6892.

[21] Z. K. Han, Y. Gao, Chem. Eur. J., 2016, 22, 2092-2099.

[22] X. J. Cui, J. P. Xiao, Y. H. Wu, P. P. Du, R. Si, H. X. Yang, H. F. Tian, J. Q. Li, W. H. Zhang, D. H. Deng, X. H. Bao, Angew. Chem. Int. Ed., 2016, 55, 6708-6712.

[23] H. L. Fei, J. C. Dong, M. J. Arellano-Jimenez, G. L. Ye, N. D. Kim, E. L. G. Samuel, Z. W. Peng, Z. Zhu, F. Qin, J. M. Bao, M. J. Yacaman, P. M. Ajayan, D. L. Chen, J. M. Tour, Nat. Commun., 2015, 6, 8668.
[24] H. B. Zhang, J. Wei, J. C. Dong, G. G. Liu, L. Shi, P. F. An, G. X. Zhao, J. T. Kong, X. J. Wang, X. G. Meng, J. Zhang, J. H. Ye, Angew. Chem. Int. Ed., 2016, 55, 14310-14314.

[25] P. Q. Yin, T. Yao, Y. Wu, L. R. Zheng, Y. Lin, W. Liu, H. X. Ju, J. F. Zhu, X. Hong, Z. X. Deng, G. Zhou, S. Q. Wei, Y. D. Li, Angew. Chem. Int. Ed., 2016, 55, 10800-10805.

[26] H. J. Qiu, Y. Ito, W. T. Cong, Y. W. Tan, P. Liu, A. Hirata, T. Fujita, Z. Tang, M. W. Chen, Angew. Chem. Int. Ed., 2015, 54, 14031-14035.

[27] F. Y. Li, Y. F. Li, X. C. Zeng, Z. F. Chen, ACS Catal., 2015, 5, 544-552.

[28] F. Dvorak, M. F. Camellone, A. Tovt, N. D. Tran, F. R. Negreiros, M. Vorokhta, T. Skala, I. Matolinova, J. Myslivecek, V. Matolin, S. Fabris, Nat. Commun., 2016, 7, 10801.

[29] L. L. Zhang, A. Q. Wang, J. T. Miller, X. Y. Liu, X. F. Yang, W. T. Wang, L. Li, Y. Q. Huang, C. Y. Mou, T. Zhang, ACS Catal., 2014, 4, 1546-1553.

[30] X. G. Li, W. T. Bi, L. Zhang, S. Tao, W. S. Chu, Q. Zhang, Y. Luo, C. Z. Wu, Y. Xie, Adv. Mater., 2016, 28, 2427-2431.

[31] J. Deng, H. B. Li, J. P. Xiao, Y. C. Tu, D. H. Deng, H. X. Yang, H. F. Tian, J. Q. Li, P. J. Ren, X. H. Bao, Energy Environ. Sci., 2015, 8, 1594-1601.

[32] Y. J. Li, L. Xu, H. B. Liu, Y. L. Li, Chem. Soc. Rev., 2014, 43, 2572-2586.

[33] G. X. Pei, X. Y. Liu, A. Q. Wang, A. F. Lee, M. A. Isaacs, L. Li, X. L. Pan, X. F. Yang, X. D. Wang, Z. J. Tai, K. Wilson, T. Zhang, ACS Catal., 2015, 5, 3717-3725.

[34] D. W. Ma, T. X. Li, Q. G. Wang, G. Yang, C. Z. He, B. Y. Ma, Z. S. Lu, Carbon, 2015, 95, 756-765.

[35] H. Furukawa, K. E. Cordova, M. O'Keeffe, O. M. Yaghi, Science, 2013, 341, 974.

[36] X. Zhang, J. G. Lei, D. H. Wu, X. D. Zhao, Y. Jing, Z. Zhou, J. Mater. Chem. A, 2016, 4, 4871-4876.

[37] S. H. Sun, G. X. Zhang, N. Gauquelin, N. Chen, J. G. Zhou, S. L. Yang, W. F. Chen, X. B. Meng, D. S. Geng, M. N. Banis, R. Y. Li, S. Y. Ye, S. Knights, G. A. Botton, T. K. Sham, X. L. Sun, Sci. Rep., 2013, 3, 1755.

\title{
非贵金属单原子催化剂的进展与展望
}

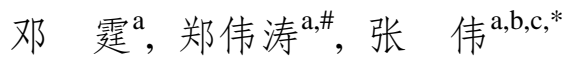 \\ a吉林大学汽车仿真与控制国家重点实验室和材料科学与工程学院, 吉林长春130012, 中国

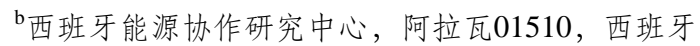 \\ ‘西班牙巴斯克科学基金会，毕尔巴鄂48013，西班牙
}

摘要: 由于良好的催化活性和稳定性, 贵金属催化剂已经被广泛应用于各种异相催化反应中, 但是贵金属的稀有性和高成 本无法满足未来日益增长的催化需求. 2011年, 张涛课题组成功地制备了高效、稳定的铂单原子催化剂. 高效的单原子催 化剂利用单个活性位点作为催化活性中心, 可能会成为连接同相催化和异相催化的桥梁. 然而从经济适用的长远角度考 虑, 将非贵金属催化剂缩小到原子尺度是否也会展现出优良的催化活性; 是否有潜力替代目前已被广泛应用的贵金属催 化剂? 虽然现阶段非贵金属催化剂的催化性能仍无法达到贵金属催化剂的标准, 但是已有相关研究从理论和实验上报道 了非贵金属单原子催化剂及其优异的性能表明了其在未来发展中极其重要, 因而, 可以预见这两个疑问的答案都是肯定 的. 单原子概念的出现不仅为提高贵金属的催化性能及成本的降低指明了方向, 同时也为制备具有高催化活性、甚至可与 贵金属催化剂相媲美的非贵金属催化剂提供了可能性. 我们在上述背景下, 阐述了对单原子的概念日益加深的机制认知, 并从理论和实验上概述了非贵金属单原子催化剂近期的发展情况, 指出了目前的在单原子催化剂领域需要解决的一些问 题, 最后, 针对研究现状, 我们对未来单原子的发展提出了相应的展望.

单原子催化剂具有较高的表面能, 因而, 如何寻找合适的基体与单原子相互作用, 进而, 使基体材料像一只手一样稳固 地“抓紧”单原子, 因而, 降低其高表面能则是发挥优良催化性能的基础. 强金属-基体相互作用(SMSI)不仅可以将单原子限 制在基体表面, 亦会影响整个催化过程. 目前应用于单原子催化剂的基体种类很多,如金属氧化物、金属以及其他材料, 而 对SMSI认知则主要分两大类, 一类是源自于基体表面的结构缺陷, 另一类是源于其电子缺陷. 从目前的发展状况来看 
SMSI机制仍有很多疑惑尚未解决, 例如对电子转移影响的认知等. 理论研究表明, 在某些反应中非贵金属单原子展示出可 替代贵金属的催化性质. 比如, 在一氧化碳优先反应(PROX)中, 单原子钴和钛展示出的催化性能可与贵金属相謧美; 理论 计算同样证明单原子镍在一氧化碳还原中的催化活性比单原子铱优秀, 甚至与单原子铂类似. 大量的实验进展也报道了 非贵金属单原子同样能在其他反应中展现出优异的性能, 如氧析出反应(OER)、氢析出反应(HER)和氧还原反应(ORR).

对于单原子催化剂, 还有很多问题需要我们去解决, 例如基体对于催化过程的具体影响、非贵金属的电子结构对于其 催化性能的影响, 以及单原子在基体上产生相互作用的位点等问题. 纵然有许多问题需要更加深入的研究, 但是单原子概 念的出现, 使得非贵金属催化剂材料取代传统贵金属催化剂成为了可能.

关键词: 单原子催化剂; 非贵金属; 催化剂; 相互作用; 催化性能

收稿日期: 2017-01-23. 接受日期: 2017-02-28. 出版日期: 2017-09-05.

*通讯联系人. 电话/传真: (0431)85168246; 电子信箱: weizhang@jlu.edu.cn

\#通讯联系人. 电话/传真: (0431)85168246; 电子信箱: wtzheng@jlu.edu.cn

基金来源：国家自然科学基金(51372095); 吉林大学学术带头人专项基金(419080500630).

本文的英文电子版由Elsevier出版社在ScienceDirect上出版(http://www.sciencedirect.com/science/journal/18722067). 